\title{
Planning for path dependence? \\ The case of a network in the Berlin-Brandenburg optics cluster
}

\author{
Jörg Sydow and Frank Lerch* \\ Department of Management \\ Freie Universität Berlin \\ Boltzmannstr. 20 \\ 14195 Berlin-Dahlem, Germany \\ Tel: 0049-30-838-53783 \\ Fax: 0049-30-838-56808 \\ joerg.sydow@fu-berlin.de \\ frank.lerch@fu-berlin.de
}

and

\section{Udo Staber}

Department of Management

University of Canterbury

Christchurch, New Zealand

Tel: 0064-3-364-2987-8613

Fax: 0064-3-364-2020

udo.staber@canterbury.ac.nz

March 15, 2009

Published in: ECONOMIC GEOGRAPHY 86 (2) 2010, pp. 173-195.

* Corresponding author: Jörg Sydow

Acknowledgements: This paper is an outcome of the research project “Assessment and Monitoring of Network Development of OpTecBB“ that was carried out in collaboration with Arnold Windeler and financed by the Berlin Senatsverwaltung für Wirtschaft, Arbeit und Frauen, with funds from the EFRE program. We are particularly grateful to our interviewees in OpTecBB for their time and trust, and to the reviewers and the editor of Economic Geography for their constructive support in developing this paper. 
Planning for path dependence?

The case of a network in the Berlin-Brandenburg optics cluster

Abstract: Much research on regional business clusters refers to path dependence as a central feature in the evolution of cluster structures. In many cases, however, little is known about the agentic processes and mechanisms underlying path dependence. In this paper, we explore changes in a specific network in the optics cluster in the German region of Berlin-Brandenburg to show that cluster development can be driven by elements of both emergence and planning. In particular, we argue that current actors actively and purposively draw upon rules and resources that were shaped not only in the long and discontinuous history of the cluster but also in the recent process of network development which involves careful planning and well-structured planning tools. Using central concepts from structuration theory, we show how agency is implicated in the coordination of the network and how agency turns coordination into a selfreinforcing mechanism. The findings suggest that purposive planning involves a fundamental ambivalence in the processes and outcomes of path dependence, both at the level of the cluster and its constituent networks.

Key words: Cluster; network; optical technologies; path dependence; structuration theory 


\section{Introduction}

Some regional business clusters develop along a single, coherent, and intentionally designed path, whereas others develop in a more haphazard and unpredictable fashion (Zucchella 2006). Regardless of the direction and coherence of development, there is broad agreement in economic geography that "path dependence is one of the fundamental features of the economic landscape” (Martin and Sunley 2006, 398), at least in the minimalist sense that, in a sequence of events, the latter events are dependent on those that occurred before them. The exact circumstances of path dependence in specific empirical instances are often difficult to document and explain, especially in those cases where development extends over long periods of time and is disrupted by major events. Little is known in these cases about the processes and mechanisms by which trajectories develop, and about the factors involved in creating, maintaining, and breaking path dependence. It is also often unclear whether path dependence is a phenomenon of emergence and downward causation or of uni-directional upward planning and design. These difficulties are compounded by the fact that the concept of path dependence is often used - not only in economic geography - more metaphorically than analytically (Sydow et al. 2009). Many investigators employ this concept at a very abstract level, using it as a general device to account for a variety of processes related to inertia, imprints, legacies, isomorphism, embeddedness, and the like, without showing concern for the different mechanisms involved at different stages and levels.

We argue in this paper that much can be learned about path dependence from an analysis that highlights human agency in the constitution of path dependence and examines pathdependent processes at a level below that of the cluster. By emphasizing agency, we wish to avoid the deterministic interpretations one can find in many studies of path dependence. In line 
with the growing interest in economic geography in the cognitive micro-foundations of socioeconomic structures like clusters and localized social networks (Ettlinger 2003; Maskell and Malmberg 2007), we draw attention to the details of human agency. New analytical insights can be gained from departing from the conventional view of path dependence as mostly an emergent phenomenon triggered by some small incidental event, driven by self-reinforcing mechanisms, many of which are beyond the control of individuals, and leading to a lock-in which is negative and can be broken, if at all, only at great cost. We suggest that agency is evident not only in actors following an existing path or creating a new one, but also in the possibility that they deliberately plan for path dependence. By "planning for path dependence” we mean a set of recurrent activities that involve monitoring the past and present, and anticipating and even initiating the future. As a "social practice" (Giddens 1984) it aims at the explicit or implicit creation or maintenance of path dependence, if it promises benefits that are larger than costs, and at the avoidance of path dependence, if it is believed to lead to a negative lock-in. Like Martin and Sunley $(2006,408)$, we think of "path as process," involving the mindful actions of agents who may or may not purposively plan for path dependence. This path process gains momentum through self-reinforcing mechanisms, such as (network) coordination. It is in this process where "planning for path dependence” is extremely important, but also very difficult to accomplish.

We think that the structuration perspective, originally developed by Anthony Giddens (1984) as a social theory, offers a useful agency-oriented and yet structure-sensitive reinterpretation of the classical path dependence theory put forward by Paul David (1985) and Brian W. Arthur (1994). It also supports an analysis of structuration processes occurring at and across multiple levels. We examine the recent development of the optic technologies cluster in the German region of Berlin-Brandenburg to show how agency is implicated in the coordination of a network within this emerging regional cluster and how agency turns coordination into a self- 
reinforcing mechanism. We build our analysis on the premise that path dependence is fundamentally ambivalent (Martin and Sunley 2006). On the one hand, path dependence has a number of desirable features, especially for clusters in-the-making like the Berlin-Brandenburg optics cluster, as positive feedback processes can accelerate the cluster's development and keep growth on the intended track. On the other hand, the same processes can also lead to negative lock-in, especially in clusters that are characterized by extensive firm-level specialization and close inter-firm collaboration. This ambivalence is typically ignored in studies of clusters that attend mostly to various forms of negative lock-in rather than the possibility that firms actively seek and plan for path dependence (Fuchs and Shapira 2005). A close look at how agency operates at the network level, how it is influenced by cluster structures and, in turn, contributes to the (re-) production of these structures, helps to understand the conditions under which one or the other outcome is most likely. We explore agency structures and processes through an embedded case study (Yin 2009), using interview data we collected in the cluster as well as in a specific network of this cluster. Our analysis highlights the tension between emergence and purposive planning, by showing how agency is implicated in the dynamic interrelationships between the network and the cluster in which it is embedded.

The paper is structured as follows. In the next section, we outline the basic elements of structuration theory, as relevant to an explanation of path dependence processes. Following a brief overview of the historical development of the Berlin-Brandenburg optic technologies cluster, we explore the nature of agency in recent efforts by various actors to create and maintain a new path in a network that is central to this cluster. Although we focus on network coordination as a potentially self-reinforcing mechanism, we also address the fundamental open-endedness of the structuration process underlying coordination. We conclude with a summary of findings that 
have general value for research on path dependence in geographic clusters, and identify several questions for further research.

\section{An Agency-Based Conceptualization of Path Dependence in Clusters}

Based on the technical-historical approach and dynamic-stochastic conceptualization suggested originally by David (1985) and Arthur (1994), respectively, researchers in the social sciences have, over the years, extended the concept of path dependence in a variety of directions. On the whole, however, those who are really interested in understanding this particular kind of process have remained close to the theoretical core (e.g., Thelen 1999; Pierson 2000; Beyer 2005;

Sydow et al. 2009). The central idea of path dependence is that one or several (serially correlated) events trigger a non-stationary process that gains momentum and keeps itself alive along a particular track. Many other researchers have employed the concept of path dependence more as a metaphor for something that every historian and most social scientists have long taken for granted, namely the idea that "history matters."

In this paper, we argue in line with those who treat path dependence as an analytical concept, but we highlight those aspects of path dependence which indicate heterogeneity and openness. We suggest that the "road map in which an established direction leads more easily one way than another” (Walker 2002, 126) should be seen more as a structuring and structured process than a fixed structure, in the sense that the road map has to be reproduced rather than merely replicated. We think that the conventional approach to the study of path dependence in cluster development puts too much emphasis on institutions - and other structures - as a set of binding constraints, leading to outcomes such as institutional "stickiness" (Markusen 1996) or "hysteresis" (№rth 1990). By their very nature, institutions do constrain. Institutions set 
expectations and impose rules, creating structures that reduce uncertainty and improve accountability. They represent ordered interaction sequences, often leading to consistency, coherence, and stability. But institutions also imply ongoing activity, which involves more or less potent actors, competing logics, and resources supporting change. Institutions themselves can change, and their origins may have little to do with the uses to which actors put them currently. The analytical task is to identify the conditions under which actors, either individually or collectively, discard old routines, bend rules, enact new resources, leave well-trodden paths, and create new paths (Garud and Karnøe 2001; Crouch and Farrell 2004), or how they consciously and intentionally remain on or extend existing paths. We suggest that this requires a theory of agency and structure to accommodate the possibility that actors purposively create and sustain path dependence which they control, at least partially, rather than merely react to.

Giddens' (1984) structuration theory provides such a theory. It views agency as both free and constrained. It shows how actors can draw on a diverse repertoire of rules and resources to structure path dependence in a way that is responsive to but not pre-determined by existing institutions (Windeler 2003). Structuration theory helps to understand path dependence as a structured and structuring process rather than a series of equilibrium states in which only those periods leading up to a lock-in or the moment of "critical juncture" are of theoretical interest. In the particular case under investigation here, we show how agency is implicated in the constitution of a path. By path constitution we mean both the intentional creation of a path (Garud and Karnøe 2001) and the maintenance of path dependence, as the actors actively and consciously follow and, if necessary, even defend a chosen path against possible alternative actions. Although agents' activities are guided by intentions, they also produce unintended consequences, not least because of "unacknowledged conditions" of their actions (Giddens 1984). Exploring the activities of agents in path constitution is in keeping with recent calls for a more fully articulated and 
differentiated approach to path dependence in economic geography (Martin and Sunley 2006) and other fields in social science (Mahoney 2000; Crouch and Farrell 2004; Sydow et al. 2009).

Structuration theory provides an analytical tool for studying path dependence across all phases of cluster development and relevant levels of analysis, while accounting for both lock-ins and discontinuities. There are at least two parts to the argument. First, the structuration concept of “reflexive monitoring” suggests that “knowledgeable agents” (Giddens 1984) actively monitor and influence structuration processes, although they normally cannot fully control them. A pathstructuration analysis is, therefore, useful for identifying and implementing measures to follow a given path, while preventing a negative lock-in. Structuration theory helps the investigator unpack historical processes, by showing how the stabilization of institutions occurs and how selfreinforcement mechanisms operate in specific circumstances. Economic geographers have drawn on various social science literatures for ideas about social mechanisms implicated in path dependence, such as learning and coordination or complementarity effects that help to create local increasing returns. However, they have often not discussed in detail the agentic processes involved when they went beyond a purely metaphoric view of path dependence. What they have increasingly done is to challenge the "actor-less accounts" of economic geographic changes (Markusen 2004) or to draw more attention to the "creative capacity of economic agents" (Boschma and Martin 2007, 537), as evident in the growing concern for the micro-foundations of economic geography related to social learning, networking, and so forth. Still, many studies that refer to agency have remained at a more general level, for example by focusing on actors’ attributes (Maskell and Malmberg 2007) and their differential capacity to intervene deliberately (MacKinnon et al. 2009), or by characterizing interaction as more or less costly (Glückler 2007). We go beyond these insights, by suggesting that agents are not merely individuals who are capable of actively monitoring their situation, making "real" decisions, and shaping agendas. The 
“agentic process” is not to be seen merely as a set of interactions between actors. We draw on Giddens’ structuration theory to describe how socially embedded actors reflect upon the process of reflection itself, to generate insights about how economic actors structure relationships and construct meaning (Piore 1995), in an environment that unfolds in the process of individuals acting upon it (Storper 2009).

In our analysis below, we focus on network coordination as a self-reinforcing mechanism that figures prominently in the Berlin-Brandenburg optic technologies cluster in form of a roadmapping exercise. The path dependence perspective, as it is normally employed, does not emphasize (network) coordination per se but refers to the economic effects resulting from coordination (North 1990). These effects, as a type of increasing return, are self-reinforcing and show the advantages of rule-guided behavior (Sydow et al. 2009): Behavior that is guided by rules can be anticipated, and the likely reactions can be taken into account. This means that the more actors adopt and apply a specific institution (such as an organizational rule or an interorganizational roadmap), the more efficient is the interaction among these actors, thereby reducing coordination costs. It thus becomes more attractive to adopt these rules, the more of the other individuals also follow these rules. In the case we discuss below, the actors have gradually transformed network coordination through structuration activities. We show that coordination is itself a mechanism that unfolds moment-by-moment through the actions and interactions of individuals, linking reciprocally developments at the network and cluster level. Structuration theory explains how path dependence evolves through coordination structures and actions.

The second aspect of the argument is that structuration theory offers a detailed account of systems as relations that are reproduced and sustained in interaction (Giddens 1984). From this perspective, social systems, such as clusters and cluster networks, are not structures, but they have structures, with properties that actors draw upon in their social interaction. "Structuration" 
refers to the very process by which actors refer to, reproduce, institutionalize, and transform these structures via social practices. Structures thus never fully determine action, but - like paths - they both constrain and enable action. Structure comes in many forms. Saxenian's (1999) comparative study of the Silicon Valley and Route 128 cluster suggests that it was partly the centralized structure of organizations and institutions in the Route 128 cluster which discouraged firms from the kind of information sharing that is often seen as a prerequisite for technological development in volatile computer and component markets. By contrast, the unique institutional environment in Silicon Valley was the main reason why firms there were able to learn collectively and experiment with new technologies and applications. Structure may be thought of as a set of rules and resources. Rules of signification ("this is how we do it”) serve as guidelines for the assignment of meaning that actors refer to when they reproduce these rules through their actions, in particular their communication. Rules of legitimation ("this is how we should do it") serve to justify the development and use of norms in social interaction. These rules are reproduced through behavior which sanctions social behavior or relationships as appropriate or inappropriate. Resources that are recursively linked to rules of signification and legitimation reflect and affect opportunities for domination and thus shape the distribution of power in the system. Giddens (1984) distinguishes between allocative and authoritative resources with which actors can translate power into domination. Allocative structures affect domination by providing access to critical resources of a material nature. Authoritative structures, as immaterial resources, enable and constrain agents in exercising power over other agents. Figure 1 provides a summary of these structuration concepts and relationships.

$<$ Figure 1 about here $>$

In sum, the development of path dependence - and the possibility of path disruption may be interpreted from structuration theory as a narrowing of the scope of strategic choices 
(Child 1997). This narrowing is produced by a "thickening" of cognitions and norms associated with signification and legitimation, and by the accumulation of allocative and authoritative resources. For example, as far as the cognitive aspect of agency is concerned, more and more of the actors in the cluster may come to agree on the benefits of a certain formal or informal rule or of certain resources that become available for further cluster development. The respective scripts - as modalities of signification - may converge in the interaction process. In this way, structuration may lead not only to a cognitive but also to a normative or resource-based lock-in (Sydow et al. 2009), depending on the mechanisms of self-reinforcement through which actors reproduce and transform social practices across time and space.

By emphasizing cognitive and normative rules, as well as authoritative and allocative resources, the structuration perspective is not only multifaceted, forcing attention to elements that induce variations in path dependence. By allowing for a "corridor" of organizational, institutional, or technological solutions, it also stands in sharp contrast to the more deterministic classical view of path dependence. And by proposing that actors are reflexively engaged in structures which they transform in the process of acting upon and through them, it is in line with recent reformulations of the classical path dependence approach which focus more on the underlying processes and possibilities of path creation and disruption (e.g., Thelen 1999; Pierson 2000; Garud and Karnøe 2001; Sydow et al. 2009). We think that structuration theory offers a useful conceptual scheme for understanding how knowledgeable actors create, maintain, and disrupt path dependence by reinforcing or weakening network and/or cluster structures as both the medium and the outcome of action. 


\section{Methods and Data Sources}

The empirical findings discussed below come from extensive research on the development of the optics cluster in the Berlin-Brandenburg region in Germany and, in particular from the embedded case (Yin 2009) of an X-ray Technology (XRA-Tech) network since the year 2000 when the association of Optic Technologies Berlin-Brandenburg (OpTecBB) was founded. Data were collected through a series of semi-structured interviews with the key players in the cluster and with focal actors in the XRA-Tech network. In total, we interviewed - in two waves (2003 and 2006) - 121 individuals working in 101 organizations in the industrial and institutional domain of this cluster. Because we were involved as observers in the development of this cluster from its beginning in 2000, we achieved a response rate of 96 percent (2003) and 88 percent (2006) of all members of OpTecBB. We interviewed representatives of almost all of the now more than 90 OpTecBB member organizations (including all 14 members of the XRA-Tech network). The structured interview guide contained questions about the history and the present governance structure, as well as the recent development process of the cluster. Apart from about a dozen interviews with the most important actors in OpTecBB and the XRA-Tech network, all interviews were conducted by telephone.

Data were also collected through participant observations by two of the authors, one of whom participated in all of the annual XRA-Tech and OpTecBB meetings and strategy workshops over a period of six years. We were also given access to minutes from meetings, documents, and presentations. In addition, we reviewed the secondary literature and internet sources for information about organizations and technologies (optics and, specifically, x-ray technologies) developed in this region. In the analysis of the interview data, for which we used concepts derived from path dependence theory and reinterpreted from a structuration perspective, 
the transcribed interviews were coded and then reviewed by each of the authors independently. The results were later discussed by the authors to arrive at a joint interpretation of the data. We begin our analysis with a brief overview of the historical origins of the cluster.

\section{Historical Underpinnings of Current Cluster Developments}

To understand recent developments in the optics cluster in Berlin-Brandenburg it is critical to be aware of factors whose origins can be traced back to the time when Germany and Berlin were divided, and even further back to imprinting conditions in the late 19th century. During the period leading up to WWII, Berlin had become a European center for the development and manufacturing of scientific instruments, precision mechanics and optics in which science and business organizations were closely interrelated (Zaun 2002). Leading Berlinbased optics companies and a range of research organizations collectively formed the technological, institutional, and (inter-) organizational foundation for the development of this cluster. The disruptions and destructions caused by major events like two world wars and the division and reunification of Germany mean that the actors today are more likely to draw on cognitive and normative structures than on particular resources created in the distant past.

After 1989, the field experienced again a major transformation that is unique when compared to developments in other West German optics regions like Wetzlar or other East German optics regions like Jena. While developments in the former West-Berlin organizations and institutions were rather gradual, with the effect of stabilizing the field, most East-Berlin optics companies and research organizations, such as the Academy of Sciences, were closed, thus releasing substantial human resources. Some of the personnel were later employed by the successor institutes. However, a large number of people formerly employed in Berlin-Adlershof - 
the location of the Academy of Sciences with its Central Institute of Optics and Spectroscopy and Center for Scientific Instruments - became unemployed and left the cluster and the region or sought employment in other industries. Nevertheless, some of them founded new firms in the newly created research and technology park in Berlin-Adlershof (Simons 2003, 52-92). The decision after German reunification to develop Adlershof as a research and technology park (focused also on optical technologies), to relocate the successor facility of the Berlin synchrotron radiation facility, a high brilliance third generation x-ray source (formerly located in WestBerlin), and to concentrate in Adlershof the natural science faculties of Humboldt University, can be seen as a critical juncture. In combination with prior decisions made by strategically placed actors, this created the "initial conditions" (Doz 1996) for the most recent development of the optics cluster in Berlin-Brandenburg.

\section{Planned Development of the Regional Cluster: OpTecBB 2000-2006}

The evolution of the cluster since 2000 has to a large extent been guided and structured by a competition initiated by the German Federal Ministry of Education and Research. This competition was aimed at promoting optical technologies in Germany through the development of regional optics clusters. It required that participating clusters submit a formal cluster development plan. In Berlin-Brandenburg, OpTecBB e.V. - an association - was formed as the administrative organization for the cluster. Representatives of regional optics firms and research organizations worked out a cluster development plan that was intended to create a new path which focused explicitly on the development of the optics cluster rather than the development of specific technologies within the cluster. However, the new path was intended to also build on past structures. This included the decision to promote especially those areas in optical 
technologies that had previously been developed in the region and in which firms either held an internationally strong position already or showed strong potential to develop a competitive position. These fields included uv- and x-ray technologies, internet-communication, bio-medical, and space and transport applications of optics. Networks were formed to stimulate innovation in each of these technology subfields, with members being recruited from industry and science in the former eastern and western parts of Berlin. The decision to concentrate on these four technology fields indicates that the actors aimed at introducing selectivity in path development. Other options for technology subfields were on the table as well, but decision makers in the early life of OpTecBB drew upon existing cluster rules and resources, thus consciously reproducing these as aspects of structure.

Our interview data show that during the six years following the founding of OpTecBB in 2000 the actors remained with these early decisions. Current network structures reflect shared views and norms, based on rules of signification and legitimation, and developed through intensive interaction. Among these views and norms are those that emphasize the strategic importance of cooperation between firms and research organizations - and even between competitors (Lerch et al. 2007). Moreover, these views and norms have never been seriously contested. Though presently under discussion, the formal governance structure of the cluster has been rather stable over a period of several years and has supported the further development of respective rules of signification and legitimation.

The network structures are also the result of several strategically placed actors in the institutional arena purposively creating a formal system of cluster governance. This system requires that each of the sub-networks be led by one representative from industry and one from research, and that these individuals also participate in the cluster board. The choice of this form of governance was intended to reflect the structural complexity of the networks. It was to put 
research and industry on an equal footing in decision making, in order to support network coordination by accounting for the technological, institutional, and organizational particularities of the various subfields in which the networks exist. The aim was not only to form an institutional bridge between the two "societal spheres" (Giddens 1984) of industry and science but also to stabilize the social space within which economic, research, and technology transfer activities can be coordinated. Although several specific aspects of this governance arrangement are currently being debated, it is not expected that any changes made would significantly alter future network and cluster developments.

Based on our observations at this stage in cluster and network development, one might be tempted to conclude that the evolving path since 2000 has been solely the result of systematic planning and coherent policy, providing an example of a "goal-directed network trajectory" (Kilduff and Tsai 2003). However, this interpretation would overlook the strong impact of historical preconditions, as well as the role of unintended consequences and unacknowledged conditions of actions. History has at various points not only facilitated but also constrained the process, leading to the development of path dependence that is, in some respects, “emergent.” Given the mainly cognitive and normative imprints of a long historical, yet disrupted tradition, as well as the variety of factors (e.g., related technologies, institutional rules, and organizational logics) involved in multi-level evolutionary processes, it seems appropriate to characterize the development of this cluster as following a path containing both intentional and emergent elements, not least with respect to network and cluster coordination. Empirical research will unlikely be able to account precisely for the multiple effects of all variables within the entire cluster and over a period of time as extended as in this case. For this reason, we focus the analysis below on path creation and maintenance in the recent development of an individual network that has been central to the evolution of this cluster. Concentrating the analysis on more recent 
developments in only one of the subfields of the cluster helps to unpack the role of agency in the evolving process and its relationship with network and cluster structures.

\section{Path Processes in a Network of the Cluster: The XRA-Tech Network}

The importance of "initial conditions" for network development in general, and network coordination in particular, is well recognized in the management literature (e.g., Doz et al. 2000; Ring et al. 2005). Less well understood are the details of the process by which initial conditions have consequences for coordination. For example, it is not always clear if it would have been possible for the actors to follow alternative routes, which contingencies led to path-dependent outcomes, and to what extent these outcomes were irreversible. Our data offer some insights into the path creation and maintenance processes in the recent evolution of the XRA-Tech network, with a focus on network coordination and the unique historical context of the optic field of technologies, institutions, and organizations. They indicate that (1) one firm in particular was instrumental in structuring a process that became self-reinforcing for the network as a whole, without closing off the potential emergence of alternative trajectories, (2) the network building process was part of a deliberate strategy to develop and follow a carefully selected technological trajectory, (3) network coordination was aided by long term personal relationships which originated under vastly different historical preconditions but had sufficient staying power to help create new structures in a different institutional regime, and (4) coordination activities at the level of projects, the network, and the cluster were linked recursively.

$<$ Figure 2 about here $>$

The XRA-Tech network is located in one of the OpTecBB subfields, the uv- and x-ray technology focus groups (Figure 2). This network, which currently comprises 14 organizations 
(seven firms and seven research institutes), was formed at the same time that OpTecBB was founded as the association representing the cluster. The initial XRA-Tech network formation process was rather open-ended, as several distinct technological fields (ultraviolet, extreme ultraviolet, soft x-ray and hard x-ray technologies) were discussed by the actors in this OpTecBB sub-field. In a series of three workshops, intended to identify technologies in which the group wanted to collaborate and generate innovations, one actor in particular (located in the hard x-ray community) communicated his understanding of the relevant technologies and how innovations might be generated. He also introduced the idea of coordinating the hard x-ray actors by means of a road map and began to develop this roadmap, while also inviting the relevant regional actors to participate in the process. The emerging exclusion of the other uv- and x-ray sub-fields from this process resulted in the narrowing of the corridor of possible technological, institutional, and organizational solutions. Coordination was to be achieved through the road map for specialized hard x-ray analytic technologies and the organizations working primarily in this area. We see here the beginnings of a structuration process that became self-reinforcing for everyone involved. Although this process was dominated by a firm which deliberately planned for path dependence, it also provided sufficient room for self-organization and the emergence of new structures.

The network governance structure that emerged was a dual authority structure, consistent with the blueprint laid out in OpTecBB's cluster development plan. It included one representative from industry, and one from the field of science. One head of the network, representing the industrial side, was a former director of the transfer oriented Institute for (x-ray) Scientific Instruments within the former East German Academy of Sciences. After reunification he had founded his own company (focusing on hard x-ray technologies) after the institute and the Academy were liquidated. He had, and still has, close connections to researchers and firms in this industry. The other head, representing the science side, is one of the directors of the Boltzmann- 
Institute for Nonlinear Optics and Spectroscopy ${ }^{1}$, the successor organization of the East German Central Institute for Optics and Spectroscopy of the Academy of Sciences. He was equally well connected to the scientific community. However, he had been socialized in the West and had been heavily involved in lobbying for optics at different political and scientific levels. The network member firms are mostly spin-offs of the liquidated Academy of Sciences or newly founded small enterprises, all of which are active in x-ray analytic technologies. Their staff comes mostly from organizations that were part of the former Academy of Sciences located in Berlin-Adlershof, particularly from the Institute for Scientific Instruments. The other members are x-ray and synchrotron research organizations previously located in West-Berlin.

The personal and organizational backgrounds of the actors demonstrate the importance of historical preconditions and "critical junctures" for network coordination and, thus, path creation. Whereas most of the research-industry relationships are organization-based, given that nearly all of the firms were founded after German reunification, the connections among the XRA-Tech network members (at least in the formation and early development of the network) stem by and large from personal relationships that had developed during the 1970 and 1980 within the Academy of Sciences and the Institute for Scientific Instruments in East-Berlin. These ties were informed by norms of science-based "business" conduct and creative cooperation that had evolved during that time. The current managers had either been former employees and doctoral students of the director of the former Institute for Scientific Instruments or former suppliers of components to this institute:

\footnotetext{
"In this specific constellation ... in these three companies, the employees are my former employees. They have emerged from the Institute for Scientific Instruments. ... They are all Institute for Scientific Instruments employees who have known one another for 20, 30 years" (CEO of Kapillarsys).
}

\footnotetext{
${ }^{1}$ Organizational names are anonymized for confidentiality reasons.
} 
Thus, most of the important cluster actors in x-ray technology are now working within the structuration parameters of the XRA-Tech network, reproducing through their interactions over time and space the existing rules of legitimation and signification, and resources of domination. The mix of formerly eastern and western actors, each with their specific socialization background, as well as changing market conditions have also led to the adaptation of these rules and resources:

"The director of the Boltzmann-Institute and I have at the very beginning of the networking
process declared this [the rules of conduct] in a statement. We have consulted all network members
included in this statement. They found it all to be more than reasonable, and so it became our
conduct" (CEO of Kapillarsys).

Thus, the way in which collaborative projects and the network itself are coordinated today includes existing aspects of coordination that were reproduced over time and aspects that were altered and adapted to fit evolving circumstances. Some of the more important coordination mechanisms of the XRA-Tech network stem from the experiences of actors in the former Academy of Sciences. The most important example of such a mechanism is the technological roadmap. The idea for this had already existed in form of an internal theme program in the Institute for Scientific Instruments, and it proved to become an important planning and coordination tool not only for reducing technological uncertainties and creating consensus among the XRA-Tech network members but also for (1) strengthening relationships among the network members, (2) overcoming much of the East-West divide in the network, and (3) governing and coordinating the newly created network:

\footnotetext{
"The roadmap has a rather strategic approach. It specifies which goals we want to reach in five years, here in Berlin. How can we bundle and concentrate our resources, and what do we need to follow to reach these goals? [...] so the big themes are coordinated here, like x-ray sources, $\mathrm{x}$-ray optics, detectors, software, and so on” (director of the Boltzmann-Institute).
}

The composition and development of a roadmap has now become, in structuration terms, an institutionalized means to guide network coordination and to reproduce the XRA-Tech 
network structure, thus contributing to its increasing stability. Current network developments occur along a path defined implicitly by this technological roadmap, which itself draws on the historical preconditions and the existing structure of the surrounding cluster:

\footnotetext{
"Due to the fact that we had developed this roadmap, we were quickly able to successfully bid as a network for financial support for this large collaborative project 'new methods in $x$-ray analysis' with 13 members from science and industry. From this project emerged not only new methodological solutions but also concrete approaches to collaboration, with the aim to develop marketable products” (director of the Boltzmann-Institute).
}

The inclusion of only Berlin-based x-ray technology organizations in the roadmap is the result of an intentional cluster and network building process that was meant to support only regional organizations. It also ensures that only the technological trajectories selected by the network members are being followed. The roadmap focuses on x-ray components and systems that the local companies develop and sell, and where the regionally based research institutions have comprehensive and internationally competitive competencies. Other firms are explicitly excluded from the roadmap and the network because they are seen as not fitting into the technology matrix. One of the authors of the present paper witnessed the deliberate exclusion of a representative from a large international laser company from a roadmap meeting just before it was to begin. The incident highlights the selectivity of roadmapping activities and of roadmapping as a strategy:

"This roadmap is not to be distributed freely because it is intended to be used by only a limited circle. [...] There is a common understanding [between the XRA-Tech network members] that the results need to be defended and protected” (director of the Boltzmann-Institute).

This may be interpreted as an indication of incipient path closure achieved through selfreinforcing coordination and intended to produce increasing returns for those who are included in the network. However, the selection process is also sufficiently open to allow the roadmap to be continually adjusted through annual consultations with scientists and representatives from the network organizations. The scientists introduce to the network state of the art knowledge which 
they acquire at conferences and through academic discourse with more distant actors. The firms bring into the network their technological and market strategies. In addition, the network members organize a bi-annual XRA-tech conference and exhibition in Berlin. They also take part in collaborative technology development projects with organizations outside the network and the region. The strategic openness with which the network actors are expected to identify new market developments and technological trends helps to minimize the risk of technological or organizational lock-in. At the same time, the actors enjoy the increased coordination benefits that result from the roadmapping exercise and the new information that is generated in this process.

Since the formation of the XRA-Tech network, the members have collaborated on numerous projects, primarily to develop new x-ray components and systems. As the CEO of one of the start-up firms commented:

“This particular project ['new methods in x-ray analysis'] has been developed within the XRATech network. It was then divided into several work packages that were worked on by different constellations of the network members. The projects mainly focused on pre-product development" (CEO of Detec).

Even though these work packages were coordinated in a decentralized project management fashion, coordination was embedded in a recursive interplay of project-based and project overarching coordination activities, as they can be observed in "project networks" (Sydow and Staber 2001) and "project ecologies" (Grabher 2005). Coordination at the project level supplemented coordination at the level of the network and the cluster. Thus, the reproduction of rules and resources in managing projects within the network had implications for the reproduction of rules and resources at the network level. In turn, the network members also drew on the network coordination rules and resources when managing their projects, thus reproducing them at a lower level. For example, in a specific project two competitors were supposed to work on the development of a new component in what in this industry is called "pre-competitive 
space”. The tensions between these two companies were "resolved" by one of the speakers for the XRA-Tech network, when he excluded one competitor from the project. By keeping the other partners in the project working together along the lines specified in the roadmap, he also reproduced his position of power in the network. The coordination potential of the roadmap becomes most obvious here: It specifies formal expectations and informally reveals what are considered legitimate forms of conduct within the network. The rules of legitimation are reproduced by network members when they actively draw upon norms or do not oppose them in their interaction, or when a powerful actor sanctions misbehavior. The CEO of Kapillarsys and speaker of the XRA-Tech network used norms explicitly, stating that in this particular network even direct competitors collaborate in the "pre-competitive space.” He exercised his power to sanction deviant behavior by excluding network partners from (future) projects, but not from the network, thus keeping the partners “on track.”

The way in which the roadmap was used not only economized on coordination. It also reinforced the social practice of network coordination within and between projects. As a result, the roadmap helped the coordination practices in this network gain momentum and stability, with consequences that spread well beyond the XRA-Tech network. The basic mechanism for achieving this may have been invisible to the actors themselves, but it can be revealed in structuration theorizing about the nature of agency in path dependence: The more the (local) xray actors exchange ideas within the framework of roadmapping and coordinate their practices, the stronger the incentive (e.g., increasing returns) to take part in the group’s network activities. The development of the XRA-Tech network shows the structurational nature of agency, as the actors shaped the evolving path of the network through their interactions and practices, even as their actions were influenced by the network. 


\section{Cluster Development through Network Development: Back from the XRA-}

\section{Tech Network to OpTecBB}

The regional XRA organizations form an active coordination core within OpTecBB through which connections to other optics companies in the region (and elsewhere) are maintained and the present cluster rules and resources are re-produced. According to the director of the Boltzmann-Institute, "the fact that we have this technological subgroup here in Berlin is good for OpTecBB as a whole.” Similar to the recursive interplay between the project and the network level, coordination at the network level influences the coordination activities at the cluster level. This is the case when, for instance, the XRA-Tech network members, and in particular the speakers of the uv- and x-ray technology sub-cluster, raise cluster coordination issues in cluster board meetings. At the same time, these cluster level activities influence coordination at the network level, thus lending them even more credibility and legitimacy.

The roadmap provides an illustrative example of this. The roadmapping process was communicated as a means to coordinate network activities in the cluster as "good practice." Since then, this idea has been picked up by other networks as well:

"This [coordination between the XRA-Tech network members] has been very successful. It has been the most complex cooperation so far. The result, the roadmap, is exemplary. It will be imitated” (OpTecBB cluster manager).

The Berlin Senate has now urged cluster actors even in other technological fields to develop specific cluster master plans. By coordinating activities at the cluster level, these plans also influence coordination activities in the XRA-Tech network, given that the optics master plan has a specific chapter on $\mathrm{x}$-ray analytic technologies which describes future strategic objectives. This shows the importance of understanding coordination mechanisms at the network level for understanding the development of path dependence - whether planned or emergent - in the entire cluster. 
At least in the case under consideration here, this process of roadmapping is, by and large, a reflective activity with respect to technology. It has proven to be important for gaining the necessary momentum and stability that characterize path development processes. This seems to be less true for the simultaneous development of the organizational properties of the network via the roadmap as a planning tool. While the members of the XRA-Tech network focused from the very beginning on technological, and even some coordination issues, the importance of roadmap development for network development has been recognized by the actors only much more recently. The increased reflexivity towards organizational issues is, so far, only noticeable at the network level, although the cluster and, possibly, the region (and its various clusters) may follow in time. Figure 3 summarizes the structuration concepts and relationships that are evident in the roadmapping process as a coordination mechanism.

$<$ Figure 3 about here $>$

\section{Path-dependence through Network Coordination?}

Collaboration among the firms and research organizations in general and, what we call "network coordination" in particular, is based on rules of signification and legitimation as well as resources of domination that have evolved during the long history of the cluster in this region. Figure 3 shows the various structuration elements of network coordination for path creation and maintenance implicated in the roadmap. From a structuration perspective, the roadmap is relevant in two ways. First, it is a result of intentional network coordination and, possibly, path creation and maintenance processes. In this respect, the roadmapping process certainly involves collaborative and deliberate planning. While the original focus of planning was solely on technological issues, at least the members of the XRA-Tech network have increasingly 
recognized that technological roadmapping has benefits also for the organizational development of the network, especially for network coordination. As the CEO of the start-up referred to above states:

\begin{abstract}
"Within this XRA-Tech network there is a pretty good coordination and collaboration. This can be seen in the periodic meetings and roadmap workshops. Here the preconditions are present so that partners can communicate with one another and develop new project ideas that are then later executed collaboratively. This has not emerged out of the blue; it is, however, also a new context that has to be seen. It is better organized. This network helps with its roadmap to get things done far more effectively and in a more concerted manner” (CEO of Detec).
\end{abstract}

Thus, the specific rules and resources which XRA-Tech network actors draw on in and through their activities have a significant impact on the speed and direction of the network's development. The roadmapping process has gained further momentum, to the point where it may even be considered self-contained. The roadmap - as a result of this process - legitimizes network organizing activities, helps to interpret specific actions as reasonable or desirable, and also entails potential sources of power. We will return to this issue below.

Second, the roadmap is also a medium of network coordination and, thus, is part of path creation and maintenance. The mapping process is, or at least could be, used by organizations, networks, and the entire cluster to reflexively create technological, institutional, and/or organizational paths. As such, it does not simply support the coordination of activities within the XRA-Tech network; it also drives network coordination and its various effects. As a consequence, it stabilizes the network and, eventually, creates or maintains not only a technological but also an institutional, and/or organizational path. The conditions that seem to foster this self-reinforcing process are found not only in the personal relationships that stem from former collaborations but also in the history of the region which the agents actively and repeatedly refer to in their organizing activities.

Whether, in light of these activities, technological roadmapping, the conditions that seem to foster the process, and the momentum and stability the process has gained over time, will 
potentially lead into new technological, institutional, and/or organizational lock-in was unclear at the time of data collection. On the one hand, the optic technology cluster in Berlin-Brandenburg belongs to a science-based field which, as a project ecology, may be less constrained by pathdependent processes (Grabher 2005). Alternatively, existing path dependencies may simply be more difficult to detect in an open field. What is clear though is that the actors in the network and the cluster are quite aware of the potential benefits of path dependence. For instance, interviewees seemed to agree that it is important for the development process of the network and the cluster to build more consensus on technological and organizational aspects of the process and to coordinate activities more tightly so that the process gains momentum. From the available data, however, we suspect that they are less aware of the risk of creating negative lock-in.

The experience of the XRA-Tech network also illustrates the power that specific actors can have in the planning and coordination process and, thereby, in path creation and maintenance. In this particular case, it is the former director of the Institute of Scientific Instruments who now acts as the director of Kapillarsys and takes on the main responsibility not only for pushing forward the technological roadmap but also for coordinating the network. By structuring the meetings, by drawing on his extensive knowledge of the technology, and by instrumentalizing the network’s social capital in the region and beyond, he can apply power and sanctioning potential in the roadmapping process. He does this, for example, with respect to prescribing in detail which technological and market alternatives are to be followed and to be formally fixed in the roadmap:

\footnotetext{
"The organization of science - that is his mentality, and that not only since yesterday but for a very long time. Back then as director of the Institute of Scientific Instruments he had quite similar tasks. In order to reach optimal results he had to coordinate different directions of analysis [representing different technologies] and he had to moderate between them. [...] then there was this idea or question [of the roadmap] and it was discussed 'what do we need?' The CEO of Kapillarsys was the fastest. He selected the partners. He has said okay, we make it that way” (CEO of X-Soft).

"The strongest promoter is the CEO of Kapillarsys. He prescribes the direction and says, 'at the end of the day these [roadmap] activities need to lead to marketable products"” (OpTecBB cluster manager).
} 
On the other hand, the power of this individual is nevertheless constrained because only the resources and technologies available in the network and the cluster can be included in the roadmap. For example, the Berlin synchrotron radiation facility, with its unique synchrotron radiation source, is highly influential in determining the range of activities in XRA technology development and applications by other organizations such as the Berlin University of Technology. The exact range of opportunities is then elaborated in the roadmapping exercise, creating a corridor of solutions for other firms, for example in x-ray optics, detector equipment, and system engineering. While the decision to expand in these technology areas may appear obvious, it was a decision made and supported by actors within the XRA-Tech network framework.

The power implied in the process, as well as the indeterminacy of present planning for path dependence, is illustrated by another project. Because the small companies in the XRA-Tech network could not provide sufficient financial resources for a prestigious research and development project, the lead partner in the project, a local research organization, selected another larger XRA-Tech company from another region in Germany as a partner:

"For this project, nobody in Berlin individually and collectively was financially potent enough. It was simply too big. [...] We took in a new company from the Rhineland as project partner. [...] However, the Berlin companies tried to avoid this up to the last minute. In the end they had to agree that it was not possible for them. The option was to cancel the project for good or at least to develop the competence here within the institute” (director of the Boltzmann-Institute).

This incident illustrates a particular project condition under which an individual actor discarded the old routines, which specified that all product development projects, for which the competencies were available in the region, should be handled by members of the XRA-Tech network. In this particular case, the allocative resources of domination available to the CEO of Kapillarsys and the other regional $\mathrm{x}$-ray companies were simply not sufficient to realize the 
project, and the companies could not even sanction the deviant behavior. This also illustrates the indeterminacy of the structuration process in which the roadmap is used as a coordination device.

\section{Discussion and Conclusion}

In line with the idea that path dependence "produces not only geography, but geography produces also path dependence” (Martin 2006, 60), we studied the recent experience of the Berlin-Brandenburg optic technology cluster as an agglomeration whose reconstitution has benefitted significantly from established interpersonal relationships and a long history. The idea that history matters is certainly not new to most social scientists who are interested in path dependence, including economic geographers. The more interesting question, of course, is how history matters and whether the influence of history differs between particular domains of path

dependence, such as technological, institutional, or organizational aspects, as well as on different levels of analysis, such as an individual network, a single organization, or an entire cluster. We can answer this question reasonably well only for the more recent development of the BerlinBrandenburg optic technology cluster and, in particular, the individual cluster network we investigated. A full explanation of all processes and mechanisms involved, and investigated at all relevant levels of analysis, would require a far more detailed historical analysis than is possible with the data available for this study and the limited space of a journal article.

Our structuration-theoretic analysis of path development in the Berlin-Brandenburg optic technology cluster yields three general findings. First, this case highlights the fact that path dependence is essentially an agentic phenomenon, calling on researchers to question the conventional focus on the constraining effects of institutions and structures in which actors are merely “located.” To understand the emergence and ambivalence of path dependence requires 
understanding how actors, as knowledgeable agents, are causally involved in a process that we recognize as path-dependent, while allowing for the influence of random, spontaneous, and context-dependent events. Agency not only plays a crucial role in mediating the interaction between pre-existing structures and evolving selection forces in general but it also produces specific results that explain why path-dependent developments can vary so much across settings, even if the same contextual conditions are in place. The analytical value of structuration theory is that it makes visible how actors enact structures - in the case of the Berlin-Brandenburg cluster, network structures in particular - and realize existing institutions, either to reproduce or to modify them. This makes this theory a valuable interpretative framework for understanding the processes implicated in path dependence, including the question of how history matters in these processes. By identifying different types of structures and actions, as well as their relationships among them, structuration theory opens up the black box of path dependence to help explain how actors negotiate their involvement in networks and/or clusters and how they reflexively assess, adjust, or resist their own and others' engagements.

Second, the literature on path dependence reveals a range of forces that are often referred to as "mechanisms" to the extent that they capture some causal sequence in the development of a given outcome. The mechanisms that are discussed include agglomeration, complementarities, learning, and network externalities. We focused in this study on the structuration of network coordination as a self-reinforcing mechanism and found that network coordination feeds into the path-dependent development of the entire regional cluster. The roadmapping procedure has had the effect of improving relationships, increasing embeddedness, and defining the boundaries of the network and the cluster more sharply so that it also facilitated inter-organizational coordination and technological innovation. The respective cost savings in coordination as well as successful innovation seem to have reinforced collaboration among the network members. Our 
analysis highlighted the XRA-Tech network’s roadmapping exercise to document some of the details of how knowledgeable agents deliberately constructed path dependence to accomplish network coordination, and how, in turn, they deliberately coordinated the network so that it eventually became path-dependent. Only with agentic intervention did network coordination become consequential for the development of the network and the cluster as a whole. The various dimensions involved in structuration explicate some of the variants underlying the positive and negative network externalities that figure so prominently in discussions of path dependence.

Third, the findings of this study point to the open-endedness of path-dependent processes. Although our interview data provide evidence of very close network coordination and collaboration, they do not suggest any signs of an impending lock-in of any kind, at least not up to this point. This may in part be due to the fact that no large corporations were involved in recent cluster building. Large firms would normally be expected to import their own organizational path dependencies into the network or cluster (Walker et al. 1997). Working against the initiation of a process of becoming locked in is the presence of many diverse and innovative project-based networks. These are more likely to create new and divergent developments than a lock-in (Grabher 2005). In spite of this, the cluster's deep historical roots in the region make an arbitrary redirection of cluster development highly unlikely. While recent developments are clearly driven by purposive planning, they are constrained by existing structures, reducing the likelihood that serendipity will play a central role. Emergence and planning, however problematic their relationship may otherwise be, go hand in hand in this case.

The risk of a negative lock-in is also reduced by the relative openness of the cluster, which is considered a central ingredient of clusters operating as effective learning regions (Hassink 2005). The openness in this case is partly supported by the diverse overlaps with organizations and institutions in other fields, such as information and communication technology, 
biotechnology, medical technology, and transportation system technology. Lock-in may be avoided especially if such overlapping is made the explicit objective of cluster management and is seen as part of reflexive network development, rather than being treated as "disturbing noise." The same holds true for the embeddedness of the regional cluster in supraregional and even international network relationships. Such connections, supported by global cluster alliances like "Global Advantage" in the area of optics or photonics (Sydow and Lerch 2007), should not necessarily be seen as a force that weakens the regional cluster. Rather, such "global pipelines" (Bathelt et al. 2004) or "mobile brokering” (Glückler 2007) through trade fairs, conventions, and interpersonal referrals may be part of the "necessary adjustments and adaptations to [the] globalization process in order to avoid 'lock-in' tendencies in the regional economy, enabling regions to stay innovative and competitive in the future as well“ (Asheim and Herstad 2005, 172). Of course, while nurturing connections with distant actors may help prevent systemic lockin (Narula 2002; Zucchella 2006), the possibility always remains that the kind of cooperative networks envisioned in official cluster policy will eventually lead to an overreliance on localized routines or a kind of "overembeddedness" in existing structures. Exploring such risks in further research would require a fine-grained analysis of reflexive cluster and network management practices.

We recognize the difficulties of generalizing findings from an individual, though embedded case study (Yin 2009), given that clusters develop in local industrial, cultural, and institutional contexts that are often unique (Hollingsworth 1998; Staber 2007). However, it is exactly such idiosyncracies which call for an intensive case study methodology, to explicate the complex processes in path dependence and to develop a basis for further research (Rueschemeyer 2003; Bennett and Elman 2006). Within the limitations of the data we collected, we suggest that much can be gained from studying variabilities in path dependence produced by the structure- 
action dynamics implied in human agency, not least with respect to "building the capacities for reflexive, collective action” (Storper 1997, 126) in regions as diverse as Berlin-Brandenburg. The findings of this study suggest several directions for further research. First, we see value in studies of newly emerging clusters rather than the conventional focus on well-established clusters. Historically informed and path-sensitive research on emerging clusters is likely to produce new insights on the processes and mechanisms by which new paths are created, either deliberately or serendipitously, because it is in the early stages that variation tends to be greatest and selection forces are strongest. Second, particularly useful would be studies which, like the present one, address developments at multiple levels to account for the recursive interplay between organizations, networks, and clusters. Such research should examine interaction effects with respect to cognitive, normative, and resource aspects of structuration across different levels of analysis, as well as with a view to the influence of self-reinforcement mechanisms in the formation and reproduction of cluster and network paths. Multi-dimensional, multi-level, and coevolutionary considerations would open an exciting field of research that should be of interest not only to economic geographers, sociologists, and historians but also to those network researchers who have often been content with comparative-static research designs and have taken a one-sided view, neglecting either the influence of activities in networks on clusters or the effect of the cluster context on the evolution of networks. Third, while our study found strong evidence of network coordination as an important mechanism with self-reinforcing consequences, the data also indicate that other mechanisms are at work as well, in particular social learning and the complementarity effects of technologies, institutions, and inter-organizational networks. Further research needs to disentangle the variety of mechanisms involved to better appreciate the multitude of forces in which agency is implicated. Understanding mechanisms should be on top of the agenda in research on path dependence. Given the high level of abstraction at which the 
propositions from structuration theory operate (Pozzebon and Pinsonneault 2005), it would also add precision to structuration concepts and to how they can be applied to the study of path dependence.

Once it is clear what exactly the object of analysis is, and once the possibility of heterogeneity and open-endedness in path dependence is recognized, we see plenty of opportunities for transdisciplinary and comparative research, bringing together perspectives that can shed new light on embedded agency. The structuration perspective appears especially wellsuited for an analysis of reflexive network and cluster developments which include emergence and planning as joint elements of (inter-) organizational processes and practices. We believe that this perspective provides a stronger theoretical basis than approaches that have informed much of the research on path dependence. It allows us to stick closely to the original concept, but without neglecting the role of reflexive agency in all phases of path-dependent development (MacKinnon et al. 2009). Following Giddens' (1984) call to put more emphasis on the duality of action and structure, we suggest that the structuration perspective avoids both the overly voluntaristic and the overly deterministic interpretations one finds in much writing on path dependence. Many studies have focused too much on serendipity in the early stages of cluster development, implying that managers and policy makers have few choices left thereafter. We suggest that path dependence is a socially dynamic process, forcing the investigator to look at structure and action simultaneously and over time and space. The structuration perspective helps to understand exactly how human agency is implicated in the construction and constitution of interdependent sequences of events and decisions. 


\section{References}

Arthur, W. B. 1989. Competing Technologies, Increasing Returns, and Lock-In by Historical Events. Economic Journal 99:116-131.Arthur, W. B. 1994. Eds. Increasing returns and path dependency in the economy. Ann Arbor: University of Michigan Press.

Asheim, B.T and Herstad, S.J. 2005. Regional innovation systems, varieties of capitalism and non-local relations: Challenges from the globalising economy. In Learning from clusters: A critical assessment from an economic-geographical perspective, ed. R. Boschma and R. Kloosterman, 169-201. Berlin: Springer.

Bathelt, H., Malmberg, A., and Maskell, P. 2004. Clusters and knowledge: Local buzz, global pipelines and the process of knowledge creation. Progress in Human Geography 28:31-56.

Bennett, A., and Elman, C. 2006. Complex causal relations and case study methods: The example of path dependence. Political Analysis 14:250-67.

Beyer, J. 2005. Pfadabhängigkeit ist nicht gleich Pfadabhängigkeit! Wider den impliziten Konservatismus eines gängigen Konzepts. Zeitschrift für Soziologie 34:5-21.

Boschma, R., and Martin, R. 2007. Editorial: Constructing an evolutionary economic Geography. Journal of Economic Geography 7: 537-548

Child, J. 1997. Strategic choice in the analysis of action, structure, organizations and environment: Retrospect and prospect. Organization Studies 18:43-76.

Crouch, C., Farrell, H. 2004. Breaking the path of institutional development? Alternatives to the new determinism. Rationality and Society 16: 5-43.

David, P. A. 1985. Clio and the economics of QWERTY. American Economic Review 75:33237.

Doz, Y. L. 1996. The evolution of cooperation in strategic alliances: Initial conditions or learning processes? Strategic Management Journal Special Issue 17:55-83.

Doz, Y. L., Olk, P. M., and Ring, P. S. 2000. Formation processes of R\&D consortia: Which path to take? Where does it lead? Strategic Management Journal 21:239-66.

Ettlinger, N. 2003. Cultural economic geography and a relational and microspace approach to trust, rationalities, networks, and change in collaborative workplaces. Journal of Economic Geography 3:145-71.

Fuchs, G., and Shapira, P. (eds.) 2005. Rethinking regional innovation and change. Berlin: Springer.

Garud, R., and Karnøe, P. 2001. Path creation as a process of mindful deviation. In Path dependence and creation, ed. R. Garud and P. Karnøe, 1-38. Mahwah, N.J.: Lawrence Erlbaum Associates.

Giddens, A. 1984. The constitution of society. Outline of the theory of structuration. Cambridge: Polity Press.

Glückler, J. 2007. Economic geography and the evolution of networks. Journal of Economic Geography 7: 619-34. 
Grabher, G. 2005. Switching ties, recombining teams: Avoiding lock-in through project organization? In Rethinking regional innovation and change, ed. G. Fuchs, and P. Shapira, 63-83. Berlin etc.: Springer.

Hassink, R. 2005. How to unlock regional economies from path dependency? From learning regions to learning clusters. European Planning Studies 13: 521-35.

Hollingsworth, J. R. 1998. New perspectives on the spatial dimensions of economic coordination: Tensions between globalization and social systems of production. Review of International Political Economy 5:482-507.

Kilduff, M., and Tsai, W. 2003. Social networks and organizations. London: Sage.

Lerch, F., Sydow, J., and Wilhelm, M. 2007. Wenn Wettbewerber zu Kooperationspartnern (gemacht) werden. In Managementforschung 17, ed. G. Schreyögg, G., and J. Sydow, 207-55. Wiesbaden: Gabler.

MacKinnon, D., Cumbers, A., Pike, A., Birch, K., and McMaster, R. 2009. Evolution in economic geography: Institutions, political economy and adaptation. Economic Geography 85 (2) (forthcoming).

Mahoney, J. 2000. Path dependence in historical sociology. Theory and Society 29:507-48.

Markusen, A. 1996. Sticky places in slippery space: A typology of industrial districts. Economic Geography 72:293-313.

Markusen, A. 2004. An actor-centered approach to economic geographic change. Annals of the Japan Association of Economic Geographers 49: 395-408.

Martin, R. 2006. Pfadabhängigkeit und die ökonomische Landschaft. In Denkanstöße zu einer anderen Geographie der Ökonomie, ed. C. Berndt, and J. Glückler, 47-76. Bielefeld: Transcript.

Martin, R., and Sunley, P. 2006. Path dependence and regional economic evolution. Journal of Economic Geography 6:395-473.

Maskell, P. and Malmberg, A. 2007. Myopia, knowledge development and cluster evolution. Journal of Economic Geography 7:603-18.

Narula, R. 2002. Innovation systems and 'inertia' in R\&D location: Norwegian firms and the role of systemic lock-in. Research Policy 31:795-816.

North, D. C. 1990. Institutions, institutional change, and economic performance. Cambridge, and New York: Cambridge University Press.

Pierson, P. 2000. Increasing returns, path dependence, and the study of politics. American Political Science Review 94:251-67.

Piore, M. 1995. Beyond individualism. Cambridge: Harvard University Press.

Pozzebon, M., and Pinsonneault, A. 2005. Challenges in conducting empirical work using structuration theory: Learning from IT research. Organization Studies 26:1353-1376.

Ring, P. S., Doz, Y. L., and Olk, P. M. 2005. Managing formation processes in R\&D consortia. California Management Review 47:137-56. 
Rueschemeyer, D. 2003. Can one or a few cases yield theoretical gains? In Comparative historical analysis in the social sciences, ed. J. Mahoney, and D. Rueschemeyer, 305-36. Cambridge, U.K., and New York: Cambridge University Press.

Saxenian, A. 1999. Comment on Kenney and von Burg 'Technology, entrepreneurship and path dependence: Industrial clustering in Silicon Valley and Route 128'. Industrial and Corporate Change 8:105-10.

Simons, K. 2003. Politische Steuerung großer Projekte. Berlin Adlershof, Neue Mitte Oberhausen, und Euralille im Vergleich. Opladen: Westdeutscher Verlag.

Staber, U. 2007. Contextualizing research on social capital in regional clusters. International Journal of Urban and Regional Research 31:505-21.

Storper, M. 1997. The regional world. London: Guilford Press.

Storper, M. 2009. Regional context and global trade. Economic Geography 85: 1-21.

Sydow, J., and Lerch, F. 2007 (with Huxham C. and Hibbert, P). Developing clusters Commonalities, contrasts and contradictions. Advanced Institute of Management Research. AIM White Paper. London.

Sydow, J. and Staber, U. 2001. The institutional embeddedness of project networks: The case of content production in German television. Regional Studies 36:223-35.

Sydow, J., Schreyögg, G., and Koch, J. 2009. Organizational path dependence: Opening the black box. Academy of Management Review 34 (forthcoming).

Thelen, K. 1999. Historical institutionalism and comparative politics. Annual Review of Political Science 2:369-404.

Walker, G, Kogut, B., and Shan, W. 1997. Social capital, structural holes and the formation of an industry network. Organization Science 8:109-25.

Walker, R. 2002. The geography of production. In A Companion to Economic Geography, ed. E. Sheppard and T. Barnes 113-32. Oxford: Blackwell.

Windeler, A. 2003. Kreation technologischer Pfade: ein strukturationstheoretischer Analyseansatz. In Managementforschung 13, ed. G. Schreyögg, and J. Sydow, 295-328. Wiesbaden: Gabler.

Yin, R.K. 2009. Case study research. $4^{\text {th }}$ Ed. Los Angeles: Sage.

Zaun, J. 2002. Instrumente für die Wissenschaft. Innovationen in der Berliner Feinmechanik und Optik 1871-1914. Berlin: Verlag für Wissenschafts- und Regionalgeschichte Engel.

Zucchella, A. 2006. Local cluster dynamics: Trajectories of mature industrial districts between decline and multiple embeddedness. Journal of Institutional Economics 2:21-44. 
Figure 1. Concepts and relationships in the reflexive structuration process

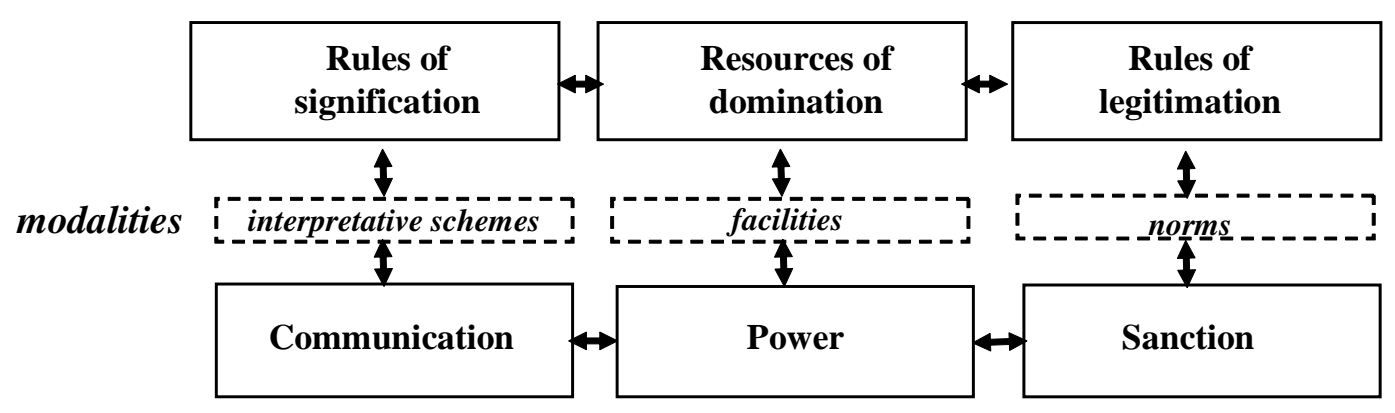


Figure 2. Schematic representation of the XRA-Tech network ${ }^{2}$ in the optics cluster in BerlinBrandenburg, showing the multiple embeddedness of actors at different levels

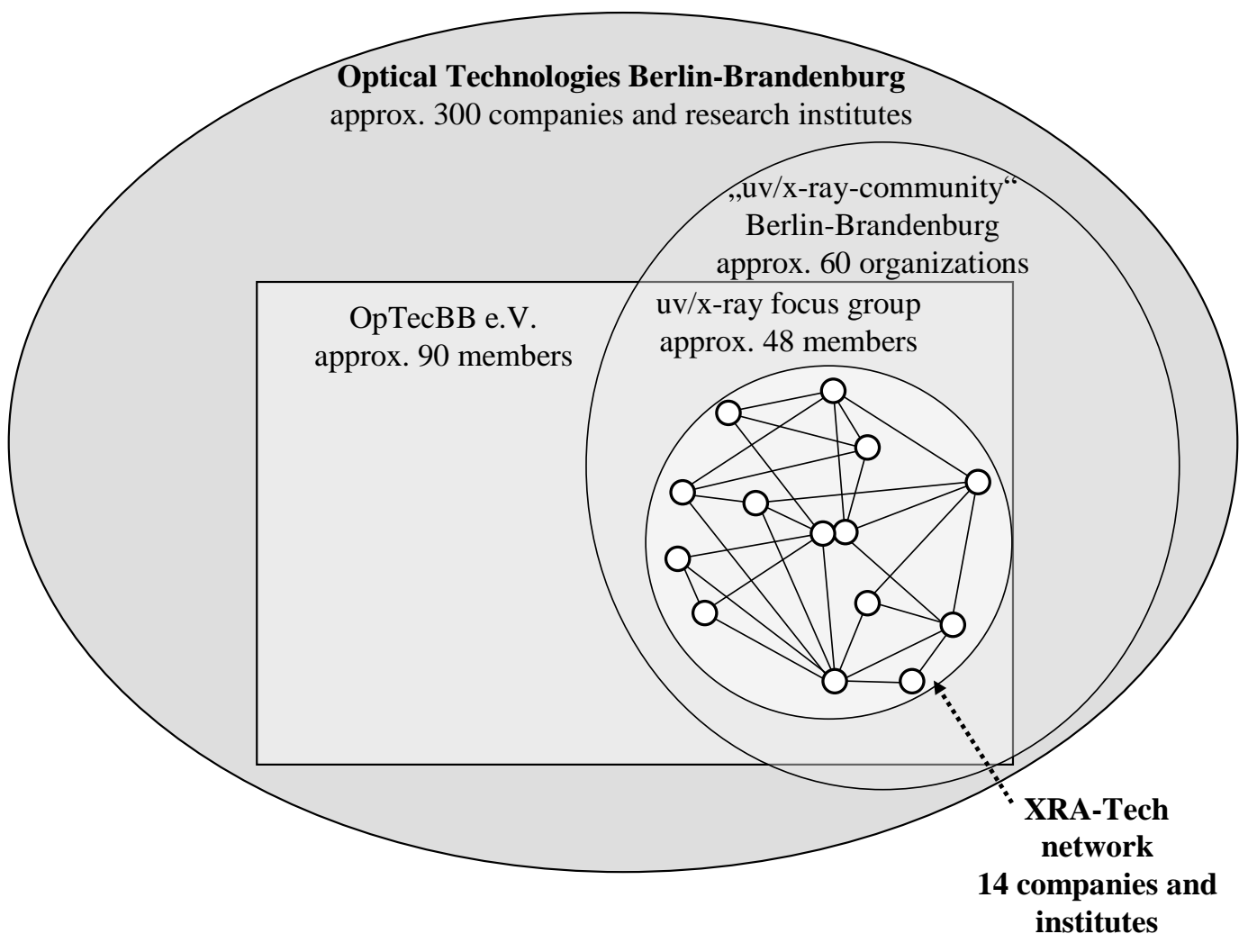

${ }^{2}$ While the XRA-Tech network companies and institutes are densely connected and form a cohesive group within the cluster, they also maintain more or less close relations with other organizations outside this network (with other OpTecBB members, other cluster organizations in the region, and organizations outside the cluster). 
Figure 3. The reflexive structuration process of the XRA-Tech roadmap as a coordination mechanism

\begin{tabular}{|c|c|c|c|}
\hline $\begin{array}{c}\text { Roadmap as } \\
\text { coordination } \\
\text { structure }\end{array}$ & \begin{tabular}{l}
\multicolumn{1}{c|}{\begin{tabular}{c}
\multicolumn{1}{c|}{ Rules of } \\
signification
\end{tabular}} \\
The roadmap assigns meaning \\
to coordination. In its codified \\
form, it highlights the market \\
and technology orientation of \\
projects and networking \\
activities of the actors in \\
industry and science. \\
The roadmap is considered by \\
all XRA network actors the \\
central tool for achieving \\
cooperation.
\end{tabular} & \begin{tabular}{l}
\multicolumn{1}{c}{$\begin{array}{c}\text { Resources of } \\
\text { domination }\end{array}$} \\
The roadmap defines the \\
technological and market \\
options within which the actors \\
operate and determines access \\
to the necessary resources. \\
The roadmap sanctions \\
decisions about which \\
organizations to include and \\
exclude in projects and in the \\
revision of the roadmap itself.
\end{tabular} & 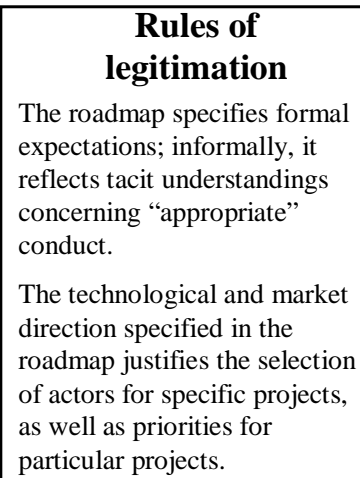 \\
\hline moda & & & \\
\hline & Communication & Power & Sanction \\
\hline $\begin{array}{c}\text { Roadmap as } \\
\text { coordination } \\
\text { through } \\
\text { interaction }\end{array}$ & $\begin{array}{l}\text { The roadmap is used to } \\
\text { communicate meanings and } \\
\text { expectations. In two annual } \\
\text { workshops, the roadmap is } \\
\text { examined, updated, and } \\
\text { adapted to new environmental } \\
\text { conditions. Roadmap activities } \\
\text { are reported in workshops and } \\
\text { at OpTecBB meetings. }\end{array}$ & $\begin{array}{l}\text { The actors who are part of } \\
\text { the roadmap have the } \\
\text { authority to make decisions } \\
\text { concerning the selection of } \\
\text { technologies and the } \\
\text { inclusion of new actors in } \\
\text { the network. } \\
\text { The roadmap is thus used as } \\
\text { an instrument of power. }\end{array}$ & $\begin{array}{l}\text { Actors can be sanctioned on } \\
\text { the basis of the roadmap. E.g., } \\
\text { if competitors do not } \\
\text { collaborate in technology } \\
\text { development, particular } \\
\text { relationships may be } \\
\text { terminated by those network } \\
\text { members who meet their } \\
\text { obligations to the network. }\end{array}$ \\
\hline
\end{tabular}

